\title{
EXTRATOS HIDROETANÓLICOS DE AÇAFRÃo E PÁPRICA PICANTE: FENÓLICOS TOTAIS E CAPACIDADE ANTIOXIDANTE
}

\author{
$\underline{\text { Ingrid Alves Santos }}{ }^{1}$; Marcondes Viana da Silva ${ }^{2}$ \\ (yngridy13@hotmail.com)
}

\begin{abstract}
${ }^{1}$ Graduanda em Engenharia de Alimentos - Universidade Estadual do Sudoeste da Bahia (UESB)
${ }^{2}$ Prof. Pleno do Departamento de Ciências Exatas e Naturais - DCEN/UESB
\end{abstract}

As ervas e as especiarias são amplamente utilizadas na dieta para realçar o sabor, cor e aroma de alimentos. Ademais, podem atuar como antioxidante e antimicrobiano natural. Na literatura estão disponíveis diversos estudos explorando a capacidade antioxidante dos constituintes fenólicos em ervas e especiarias. Os antioxidantes destacam-se por retardar ou inibir a lipoperoxidação durante o armazenamento dos alimentos gordurosos. Extratos de especiarias contém diversos constituintes bioativos, dentre os quais se destacam os polifenóis com ampla funcionalidade antioxidante. Objetivou-se determinar o teor de constituintes fenólicos totais (CFT), bem como, a capacidade antioxidante do açafrão (Curcuma longa) e da páprica (Capsicum annuum L.), especiarias amplamente consumidas. As matérias primas foram obtidas no comércio do município de Itapetinga (BA). Os extratos hidroetanólicos (etanol:água, 80:20 v.v ${ }^{-1}$ ) foram obtidos por extração assistida por ultrassom durante 30 minutos. Os CFT foram quantificados a $773 \mathrm{~nm}$ em espectrofotômetro utilizando o reagente Folin-Ciocalteu (RFC); os resultados foram expressos em equivalentes de ácido gálico $100 \mathrm{~g}^{-}$

${ }^{1}$ da amostra. O poder redutor (PR) foi estabelecido com base na redução do $\mathrm{Fe}$ (III) a Fe (II) em meio tamponado, sendo os resultados expressos em $\mathrm{EC}_{50}\left(\mathrm{mg} \cdot \mathrm{mL}^{-1}\right)$. Para a degradação oxidativa da $\alpha-2$ desoxirribose (2-DR) os resultados foram expressos em porcentagem de inibição oxidativa. Determinou-se a capacidade antioxidante pelo método do radical $\mathrm{ABTS}^{++}$a $734 \mathrm{~nm}$ e os resultados foram expressos em $\mu \mathrm{M}$ trolox. $\mathrm{g}^{-1}$. O açafrão destacou-se quanto aos teores de CFT $(253,24 \pm 1,72 \mathrm{mg}$

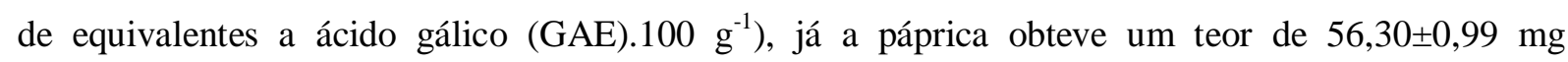
GAE. $100 \mathrm{~g}^{-1}$. Para os ensaios da capacidade antioxidante avaliada pelo PR, pelo radical $\mathrm{ABTS}^{\cdot+}$ e pela

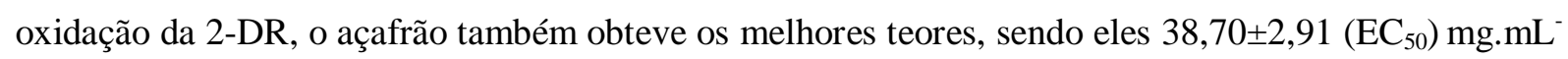
${ }^{1}, 24,52 \pm 1,99 \mu \mathrm{M}$ trolox.g ${ }^{-1}$ e 74,08 $\pm 1,50 \%$ respectivamente. Já a páprica obteve para o PR um teor de $52,36 \pm 2,32\left(\mathrm{EC}_{50}\right) \mathrm{mg} \cdot \mathrm{mL}^{-1}, 2,55 \pm 0,20 \mu \mathrm{M}$ trolox. $\mathrm{g}^{-1}$ para o ABTS e de $64,11 \pm 2,46 \%$ para a 2 -DR. Constatou-se que as especiarias estudadas são boas fontes de antioxidantes. O extrato do açafrão destacou-se dentre as especiarias estudadas pelo teor de (CFT) e pela capacidade antioxidante. As especiarias estudadas podem ser consideradas como fontes dietéticas de antioxidantes naturais podendo contribuir na redução do estresse oxidativo em humanos, devendo o seu consumo ser estimulado.

PALAVRAS-CHAVE: Curcuma longa, Capsicum annuum L., constituintes bioativos. 